ARTIGO

\title{
FORMAÇÃO DE PROFESSORES A PARTIR DAS PRÁTICAS INCLUSIVAS E DESIGN UNIVERSAL PARA APRENDIZAGEM
}

\author{
TEACHER EDUCATION FROM INCLUDING PRACTICES AND UNIVERSAL DESIGN
}

FOR LEARNING

\section{FORMACIÓN DOCENTE DESDE PRÁCTICAS INCLUIDAS Y DISEÑO UNIVERSAL PARA EL APRENDIZAJE}

\author{
Adriana de Jesus Arroio Agostini \\ Universidade Municipal de São Caetano - Brasil \\ Elizabete Cristina Costa Renders \\ Universidade Municipal de São Caetano - Brasil
}

\begin{abstract}
Resumo: O presente artigo apresenta resultados de uma pesquisa de mestrado em educação que coloca em questão a formação docente no campo da educação inclusiva. Parte da seguinte pergunta investigativa: quais são as contribuições do Design Universal para Aprendizagem (DUA), ou Universal Design for Learning, em inglês, à formação continuada de professores para as práticas da educação especial e inclusiva? Com abordagem qualitativa, por meio de método que combinou a pesquisa narrativa e pesquisa de desenvolvimento, o objetivo foi analisar como os princípios do DUA, aplicados à formação docente, podem contribuir para as práticas inclusivas na escola. Participaram da pesquisa seis professoras atuantes nos anos iniciais do ensino fundamental em uma rede pública na região do $\mathrm{ABCD}$ paulista. Os resultados mostraram a importância de a formação partir das práticas cotidianas dos professores, valorizando seus saberes e fazeres na articulação com novos conhecimentos teóricos (no caso, o DUA) para subsidiar as análises e reflexões acerca das práticas de ensino no contexto da educação especial na perspectiva inclusiva. Insere-se no âmbito do projeto regular N. 2017/20862-8, FAPESP.
\end{abstract}

Palavras-chave: desenvolvimento profissional docente; Design Universal para Aprendizagem; práticas de ensino inclusivas.

Abstract: This article presents the results of a master's research in education that calls into question teacher training in the field of inclusive education. Part of the following investigative question: What are the contributions of Universal Design for Learning (UDL) to continuing teacher education for special and inclusive education practices? With a qualitative approach, through a method that combined narrative research and development research, the objective was to analyze how the principles of UDL, applied to teacher training, can contribute to inclusive practices in school. Six teachers participating in the research participated in the initial years of elementary school in a public school in the region of $\mathrm{ABCD}$ in São Paulo. The results showed the importance of training based on the daily practices of teachers, valuing their knowledge and actions in conjunction with new theoretical knowledge (in this 
case, the UDL) to support the analysis and reflections on teaching practices in the context of special education in inclusive perspective. Research grant \#2017/20862-8, São Paulo Research Foundation (FAPESP).

Keywords: Universal design for learning; teacher professional development; inclusive teaching practices.

Resumen: Este artículo presenta los resultados de una investigación de maestría en educación que cuestiona la formación del profesorado en el campo de la educación inclusiva. Parte de la siguiente pregunta de investigación: ¿Cuáles son las contribuciones del Diseño Universal para el Aprendizaje (DUA) a la formación continua del profesorado para las prácticas de educación especial e inclusiva? Con un enfoque cualitativo, utilizando un método que combinó la investigación narrativa y la investigación del desarrollo, el objetivo fue analizar cómo los principios de DUA, aplicados a la formación docente, pueden contribuir a las prácticas inclusivas en la escuela. Seis profesores participantes en la investigación participaron en los primeros años de la escuela primaria en una escuela pública de la región de $\mathrm{ABCD}$ en São Paulo. Los resultados evidenciaron la importancia de la formación basada en las prácticas cotidianas de los docentes, valorando sus conocimientos y acciones en conjunto con los nuevos conocimientos teóricos (en este caso, la DUA) para sustentar el análisis y las reflexiones sobre las prácticas docentes en el contexto de la educación especial en perspectiva inclusiva. Forma parte del proyecto ordinario N. 2017 / 20862-8, FAPESP.

Palabras clave: Diseño universal para el aprendizaje; desarollo prefosional docente; prácticas de enseñanza inclusivas.

\section{Introdução}

Os sistemas de ensino no Brasil são regulamentados por uma legislação que traz diretrizes para a construção de uma educação inclusiva equitativa, de qualidade e para todos. No entanto, os direitos de acesso e permanência de alunos público-alvo da educação especial $(\mathrm{PAEE})^{1}$ no sistema de ensino regular não têm garantido que as escolas ofereçam um atendimento que considere as diferenças e que oportunize a participação de todos no processo de ensino e aprendizagem. Dessa forma, a escola inclusiva não pode ser pensada apenas como um espaço a ser adequado com rampas, mobiliários e recursos de acessibilidade física e comunicacional. Faz-se necessário o investimento na formação e capacitação dos professores. Esse último eixo é central para implementação da escola inclusiva, pois são os professores que vivenciam diariamente os desafios das diferenças nas salas de aula.

Nesse cenário, são frequentes as reclamações dos professores quanto ao despreparo e à carência de formações práticas no que diz respeito à transversalidade da educação especial no sistema regular de ensino. Isso os conduz à procura por formações que ofereçam modelos prontos para aplicação rápida, de modo a sanar as dificuldades dos professores no planejamento

\footnotetext{
${ }^{1} \mathrm{O}$ público-alvo da educação especial são as pessoas com deficiência, transtornos globais do desenvolvimento e com altas habilidades/superdotação (BRASIL, 2008).
} 
do ensino desses estudantes. A partir de uma escuta atenta das pesquisadoras aos professores, surgem as inquietações iniciais desta pesquisa: o que seria uma formação prática para a educação inclusiva? É possível prática sem repertório teórico consistente sobre o paradigma da inclusão?

Na procura por respostas, nos aproximamos do Design Universal para Aprendizagem (DUA) ${ }^{2}$, ou Universal Design for Learning, em inglês, que propõe estratégias para planejamentos de ensino que minimizem as barreiras curriculares na escola. Este artigo apresenta os resultados de uma pesquisa de mestrado que partiu das dificuldades enfrentadas pelos professores no processo de construção das práticas de ensino inclusivas. Perguntamos, portanto, quais as contribuições do DUA à formação de professores para a prática da educação especial e inclusiva? Metodologicamente, trata-se de uma investigação qualitativa e aplicada, empregando método combinado entre a pesquisa narrativa e a pesquisa de desenvolvimento, tendo como instrumentos de coleta de dados os relatos de experiências das práticas inclusivas docentes e as rodas de conversa.

\section{Os desafios do desenvolvimento profissional docente para educação especial na perspectiva inclusiva}

No Brasil, a proposta da educação para todos começou a se constituir com a promulgação da Constituição Federal de 1988, com a garantia da igualdade de acesso e permanência nas escolas, e do Atendimento Educacional Especializado (AEE) no sistema regular de ensino. Nesse sentido, a Política Nacional de Educação Especial na Perspectiva da Educação Inclusiva, publicada em 2008, passou a orientar os sistemas de ensino para a proposta inclusiva, reafirmando-a como essencial para romper com o modelo de exclusão. Essa política define a transversalidade da educação especial, orientando como deve se dar o AEE nas unidades escolares de todo país.

Segundo Mantoan (2018), a Política Nacional de Educação Especial na Perspectiva Inclusiva (BRASIL, 2008) compreende a deficiência a partir do modelo social, que a considera não como um problema individual, mas como algo também produzido pelo contexto social. Dessa forma, exige-se que as barreiras existentes nos ambientes sejam removidas.

Quanto ao AEE, a referida política orienta que ocorra preferencialmente nas salas de recurso multifuncionais, no contraturno do período frequentado pelo aluno na sala regular, com acesso a recursos de acessibilidade a partir da utilização de materiais didáticos e pedagógicos,

\footnotetext{
${ }^{2}$ Utilizamos o termo "design", em inglês, por entender que o termo "desenho" não representa o campo semântico do original.
} 
mobiliários e equipamentos, dos sistemas de comunicação, entre outros. Assim, seria possível assegurar as condições de acesso ao currículo, complementando ou suplementando as aprendizagens (BRASIL, 2009). No entanto, para possibilitar o acesso ao currículo, faz-se necessário refletir acerca da formação e do preparo dos professores para lidar com os diferentes saberes e ritmos de aprendizagem de todos, inclusive dos alunos PAEE, no contexto da sala de aula comum.

A publicação das Diretrizes Nacionais para a Educação Especial na Educação Básica (BRASIL, 2001) explicitou que para atuação na sala de aula regular, o professor deve ser capacitado, ou seja, comprovar ter cursado disciplinas ou conteúdos sobre educação especial na sua formação de nível médio ou superior e desenvolvido competências que possibilitem:

I - perceber as necessidades especificas dos alunos;

II - flexibilizar a ação pedagógica nas diferentes áreas do conhecimento;

III - avaliar continuamente a eficácia do processo educativo;

IV - atuar em equipe, inclusive com professores especializados em educação especial. (BRASIL, 2001, p. 30-31).

A despeito das Diretrizes Nacionais para a Educação Especial na Educação Básica indicarem há mais de 20 anos a importância da capacitação dos professores sobre a temática da educação especial e inclusiva para atuação nas salas regulares, a inserção desses conteúdos nos projetos dos cursos de licenciaturas permanece como não obrigatória. Vale questionar se os professores que não acessaram esses conhecimentos por meio das disciplinas de educação especial e inclusiva nos cursos de formação superior podem se declarar "não capacitados" e, por isso, negligenciar o ensino em uma perspectiva inclusiva. Entendemos que não, pois a legislação vigente garante o direito ao acesso e permanência de alunos PAEE nas escolas de ensino comum desde a publicação da Constituição Federal de 1988. Isso significa que todos os professores formados para exercer o magistério nos últimos trinta anos deveriam estar cientes de que a educação é para todos.

Há um percurso necessário ao professor recém-formado para que se sinta preparado para lidar com os múltiplos desafios da docência. Para Marcelo (2010), esses desafios do início da carreira exigem tempo para desenvolver estratégias de adaptação, passar pela transição entre saberes e fazeres e conservar-se abertos aos novos conhecimentos. Isso revela que não é possível aprender tudo sobre a docência e o processo de ensino no breve período de três ou quatro anos da formação inicial, pois muitas coisas só podem ser aprendidas na prática.

Além disso, o fazer docente é permeado por diferentes teorias e métodos, constantemente revisados e atualizados, visando responder aos problemas da educação escolar na atualidade. Por isso, reafirma-se a necessária articulação entre as etapas de formação inicial 
e continuada, que possibilitam ao professor continuar ampliando seus saberes, sendo um dever ético formar-se e capacitar-se permanentemente para o exercício da docência (FREIRE, 1997). Importa destacar que a Lei n. $^{\circ} 11.738$, de 2008 , destinou um terço da jornada diária docente para as atividades sem alunos, partindo do pressuposto de que o trabalho do professor não se finda na sala de aula, mas demanda planejamento, preparação de aulas e momentos formativos. A implementação dessa lei poderia oportunizar o desenvolvimento profissional em serviço através de ações planejadas. No entanto, essa organização ainda ocorre de maneira distinta nas escolas, dependendo da interpretação de cada rede de ensino.

Entre as ações de formação em serviço, destaca-se como prática comum nas escolas as reuniões coletivas semanais, que se constituem como encontros obrigatórios para todos os professores da unidade escolar e equipe gestora, realizados no período contrário às aulas com os alunos e previstas na carga horária semanal de trabalho. Essas reuniões pedagógicas são consideradas um espaço privilegiado para a discussão e reflexão acerca das práticas pedagógicas. Entretanto, muitas vezes, as reuniões assumem caráter apenas informativo para assuntos administrativos e burocráticos e por isso nem sempre alcançam o objetivo de ser um espaço de troca e desenvolvimento profissional (SANTOS, 2010).

Existem preocupações em relação às ações de formação continuada, que, de acordo com Pimenta (2012), são frequentemente direcionadas para atualizar ou suplementar conteúdos teóricos que pouco contribuem para mudanças nas práticas de ensino. Isso contribuiu para que alguns professores fiquem com "o corpo e a cabeça cheia de teorias, de livros, de teses, de autores, mas não sabem como aquilo tudo se transforma em prática, como aquilo tudo se organiza numa prática coerente" (NÓVOA, 2006, p. 14).

Modelos de formação que não atendem às necessidades de mudança das práticas educativas precisam ser repensados. Faz-se necessário buscar outras possibilidades para qualificar esses momentos formativos. Pimenta (2012) indica uma proposta de trabalho crítico e reflexivo a partir das práticas, por meio do compartilhamento das experiências vivenciadas no coletivo escolar.

Ademais, criar momentos de formação coletiva coaduna com a proposta da valorização do local de trabalho como um espaço de produção, transformação e mobilização de saberes. Portanto, como propõe Tardif (2014), coloca-se o professor como sujeito ativo, capaz de reconhecer que sua prática não é apenas aplicação de conceitos teóricos. Isso vai ao encontro do que propõe o desenvolvimento contínuo e permanente, pois "não é a prática que é formadora, mas sim a reflexão sobre a prática. É a capacidade de refletirmos e analisarmos" (NÓVOA, 2006, p. 16). 
Propor que a formação ocorra a partir da análise e reflexão das práticas pode oportunizar maior interesse e envolvimento dos professores, a partir da identificação com os relatos de situações reais de ensino vivenciadas no contexto das escolas onde atuam. Ainda sobre essa proposta de formação coletiva, Nóvoa (2009) define que:

Ser professor é compreender os sentidos da instituição escolar, integrar-se numa profissão, aprender com os colegas mais experientes. É na escola e no diálogo com os outros professores que se aprende a profissão. O registro das práticas, a reflexão sobre o trabalho e o exercício da avaliação são elementos centrais para o aperfeiçoamento e a inovação. São estas rotinas que fazem avançar a profissão. (NÓVOA, 2009, p. 30).

Para Freire (1996), a partir da análise crítica do que foi feito ontem, é possível qualificar o fazer docente de amanhã, reforçando, assim, o sentido de uma formação que ocorra ao longo da vida, pois a escola muda e exige respostas para as novas demandas. No que diz respeito aos desafios do desenvolvimento profissional docente no campo da educação especial na perspectiva inclusiva, ainda persistem algumas demandas importantes. Dentre elas, podemos destacar as discussões acerca do modelo social de deficiência que, apesar de não serem recentes, repercutiram pouco no sistema de ensino, em que ainda prevalece a prática dos encaminhamentos de alunos para avaliações e diagnósticos, conforme orienta o modelo médico.

Essa prática persistente dos professores em abordar a deficiência pelo viés do modelo médico pode ocorrer, principalmente, em dois aspectos: por um lado, há o despreparo para lidar com os diferentes ritmos de aprendizagem, por isso busca-se nos diagnósticos a confirmação de que a dificuldade está no aluno, não no ensino; por outro lado, há os conhecimentos provenientes dos cursos de formação que foram oferecidos durante muito tempo por áreas das deficiências, conforme coloca Costa-Renders (2018):

No caso da educação especial, o paradigma dominante que se pretende superar nesta contemporaneidade é a perspectiva médica que insiste no treinamento de professores e professoras para lidar com as deficiências, ignorando o sujeito em questão - o sujeito aprendente que é o ser humano. Nesse sentido, uma das ciladas possíveis na formação de professores e professoras para a educação especial é a redução do fazer docente ao cumprimento de passos recebidos em treinamentos para professor/a especialista em uma ou outra deficiência, reduzindo o processo pedagógico ao diagnóstico e ao o-que-fazer no sentido de uma receita padrão para o fazer docente cotidiano. (COSTA-RENDERS, 2018, p. 60).

A educação inclusiva coloca como um dos seus princípios que todos os alunos são capazes de aprender, ainda que necessitem de mais tempo ou de caminhos diferenciados, sendo necessário que a escola e os professores oportunizem múltiplas formas de ensino e valorizem "as diferenças de opiniões, de interesses, de necessidades, de ideias e de escolhas" de cada um (MACHADO, 2011, p. 70). Ser diferente é inerente ao ser humano, o que o torna singular na 
sua interação com o mundo e com os demais. A participação de todos, sem discriminação, é o que propõe a educação especial e inclusiva, considerando a igualdade e diferença como valores inseparáveis na construção de um sistema de ensino equitativo, pois é urgente "[...] contrariar este modo de ser e de estar da escola tradicional [...]" (MELRO, 2003, p. 56).

A equidade no sistema de ensino torna-se um desafio para o desenvolvimento profissional docente, pois os professores precisam ser capazes "de colocar em prática os mecanismos de diferenciação pedagógica" (NÓVOA, 2006, p. 8), abandonando as ideias de uma pedagogia tradicional, que trata todos os alunos como se fossem iguais, ao entender que cada um é diferente e, por isso, aprende de formas diferentes. Nesse sentido, nos reportamos à abordagem do DUA, pois entendemos que colabora com a ressignificação das práticas através de seus princípios e diretrizes, investindo em ações, estratégias, materiais e recursos que alargam as possibilidades de aprendizagem, considerando o respeito à diversidade dos alunos no sistema de ensino.

\section{O Design Universal para Aprendizagem como abordagem curricular inclusiva que apoia os professores}

O Universal Design for Learning (UDL), traduzido nesta pesquisa como Design Universal para Aprendizagem (DUA), surge da fundação do Center for Applied Special Technology (CAST), pelos médicos David Rose e Anne Meyer, em parceria com outros pesquisadores, em 1984, com a proposta de criar soluções para os desafios relativos à aprendizagem escolar de estudantes com deficiência. Eles propunham a utilização dos recursos e ferramentas digitais para atender aos alunos nas suas diferenças individuais, ampliando pontos fortes e apoiando os pontos fracos, tendo em vista que:

[...] um aluno brilhante que tem problemas para ler um texto pode ser visto como tendo uma 'deficiência' em um ambiente onde o texto impresso é o único caminho para o conteúdo, mas pode funcionar em alto nível se fornecidas formas alternativas de obter informações [...] (MEYER; ROSE; GORDON, 2014, p. 7, tradução nossa).

As experiências vivenciadas ao longo do tempo pelo grupo possibilitaram a percepção de que as ferramentas digitais poderiam colaborar para a diminuição do número de crianças rotuladas nas escolas ou encaminhadas aos serviços de avaliação e diagnósticos, se utilizadas para apoiar a aprendizagem de todos os alunos, não só aqueles com deficiência. Isso causou uma mudança no foco da abordagem do CAST, que, no final da década de 1990, passou a direcionar sua abordagem para as deficiências das escolas, ao invés das deficiências dos estudantes. 
A partir dessa mudança surge o Design Universal para Aprendizagem, que passa a considerar a aprendizagem em um contexto de interação entre o indivíduo e o ambiente. Define-se, então, o DUA como "[...] uma estrutura para orientar o design de ambientes de aprendizado que sejam acessíveis e desafiadores para todos" (CAST, 2018, tradução nossa), apoiando experiências de ensino a partir do modo como cada indivíduo se envolve no aprendizado. Destaca-se que pensam interferir no design do ambiente de aprendizagem e não no processo de aprendizagem de cada um. A partir dos estudos da neurociência cognitiva, afirmam a existência de variações nos estilos de aprendizagem de cada indivíduo, desmistificando a existência de um aluno definido como médio, comum ou padrão. Isso coloca o planejamento de ensino e o ambiente de aprendizagem como o problema, não o aluno.

Quando o ambiente de aprendizagem é flexível, a variabilidade é considerada desde o início e a diversidade é esperada, pois ocorre "[...] tanto entre indivíduos quanto dentro de indivíduos, ao longo do tempo e em diferentes contextos, acontece de muitas maneiras, impacta e é impactada pelo jeito como aprendemos e ensinamos [...]" (MEYER; ROSE; GORDON, 2014, p. 32, tradução nossa). Em vista disso, o DUA desenvolveu uma estrutura para apoiar o planejamento de ensino, de forma flexível, a qual prevê a diversidade dos alunos, propondo princípios, diretrizes e pontos de verificação, baseados nas três grandes redes neurais de aprendizagem, conforme demonstrado no Quadro 1.

Quadro 1 - Diferentes redes neurais para a aprendizagem

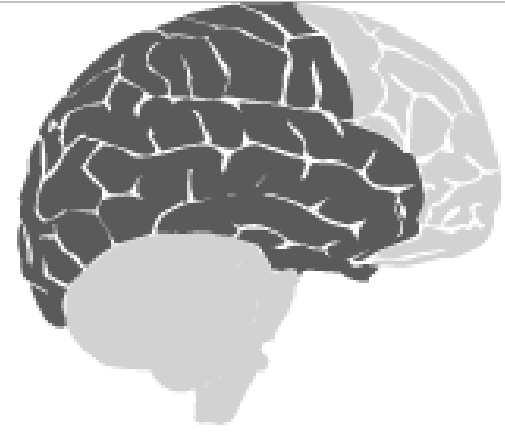

Redes de Reconhecimento $\mathrm{O}$ "o quê" aprender

Relacionam-se com a coleta, identificação e análise das informações através dos sentidos, transformando essas informações em conhecimento, por meio da associação das novas informações às antigas.

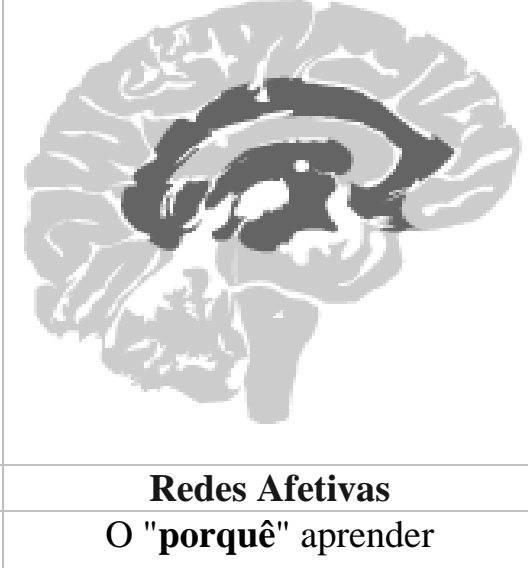

Relacionam-se com as emoções, motivações, capacidade de autorregulação e como os alunos monitoram o ambiente interno e externo para definir prioridades. São responsáveis pelo significado emocional e motivacional do ambiente ao nosso redor, motivando e priorizando o que fazemos e aprendemos.

Fonte: Adaptado de CAST (2018, p. 2, tradução nossa).

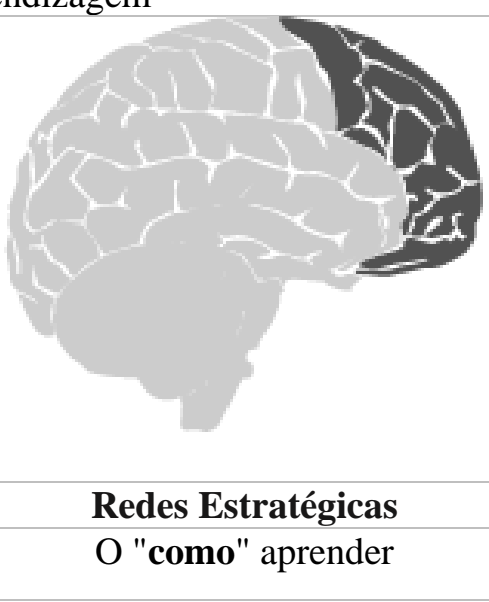

Relacionam-se com a definição de metas, de ações de longo prazo, planejamento, execução, monitoramento do progresso e correção no percurso quando necessário. São responsáveis pelas funções executivas. 
Embora existam milhares de redes identificadas pelas neurociências, a proposta do DUA considerou essas três redes primárias como as principais, e compreende-se que, em conjunto, elas são significativas para o aprendizado. Para Meyer, Rose e Gordon (2014), esse modelo simplifica a complexidade do cérebro, destacando como ocorre seu funcionamento no processo de aprendizagem.

A estrutura do DUA apresenta três princípios orientadores para apoiar a elaboração dos objetivos de ensino, seleção dos métodos, estratégias e escolhas de ferramentas, com vistas a minimizar as possíveis barreiras presentes no ambiente de ensino e aprendizagem para todos os alunos. São eles: princípio I - utilizar múltiplos meios de representação do conteúdo; princípio II - utilizar múltiplos meios de ação e expressão; princípio III - oportunizar múltiplas formas de engajamento (CAST, 2018).

Para cada princípio foram desenvolvidas diretrizes que funcionam como uma lente de aumento com o intuito de auxiliar o professor na organização dos conteúdos e propostas de ensino, permitindo a visualização da sala de aula a partir da variabilidade dos alunos. Para cada diretriz, são elencados pontos de verificação, que ampliam a percepção dos professores acerca dos múltiplos meios que podem ser utilizados no planejamento para possibilitar o acesso e participação de todos os alunos.

A proposta da estrutura do DUA não é um processo estático, segundo Meyer, Rose e Gordon (2014), mas sim uma experiência de aprendizagem contínua e dinâmica. Desse modo, as diretrizes e os pontos de verificação organizados pelo DUA são instrumentos para apoiar a implementação da abordagem curricular nas escolas, amparando a reflexão acerca do acesso ao currículo de qualquer disciplina ou etapa de ensino.

Importa destacar que tanto os princípios quanto as diretrizes e os pontos de verificação da estrutura DUA não são listas a serem seguidas de forma engessada, como um modelo de passo a passo. Ao contrário, são orientações que se ajustam às necessidades de cada professor, podendo ser guias na elaboração de estratégias e ambientes de ensino flexíveis e acessíveis aos alunos.

O DUA pode ser desenvolvido a partir de três diferentes dimensões: para o sistema de ensino como um todo, com o foco na promoção da colaboração na comunidade escolar; para os alunos, com foco no currículo e na aprendizagem; e para os professores, como uma abordagem curricular de apoio ao planejamento e ensino, sempre com a perspectiva de elevar ao máximo as oportunidades de aprendizagem para todos. Por isso, ainda que o sistema de ensino municipal ou a escola, por meio do Projeto Político Pedagógico, não fundamente suas concepções na abordagem DUA, é possível e totalmente viável para o professor implementar individualmente 
a proposta na sala de aula, a partir do conhecimento dos princípios, das diretrizes e dos pontos de verificação.

A implementação a partir da prática do professor somente torna-se possível diante de uma proposta curricular que seja aberta e permita a autonomia docente e a "[...] criatividade, dinamismo e flexibilidade em respeito aos diferentes contextos de sua aplicação e, particularmente, à diversidade do alunado" (CARVALHO 2014, p. 105). Para Meyer, Rose e Gordon (2014), um currículo torna-se flexível quando se ajusta às necessidades, interesses e preferências individuais dos alunos e estimula que, ao planejar, o professor explore múltiplos caminhos, com vistas a alargar as possibilidades apresentadas pelo ambiente de aprendizagem aos alunos, abrangendo os diferentes ritmos e saberes existentes na sala de aula.

A proposta do DUA, como já exposto anteriormente, visa promover o acesso ao currículo para todos. No entanto, não determina que os alunos com deficiências não necessitem de métodos, materiais, recursos específicos ou acompanhamento do professor especialista, pois isso seria contrário ao que preconiza a abordagem do DUA, que propõe o uso de diversos recursos como apoio para maximizar as possibilidades de acesso aos objetivos de ensino.

Essa é uma característica da proposta do DUA desenvolvida nesta pesquisa: a partir das necessidades específicas apresentadas por alguns alunos, provocar a reflexão dos professores sobre as possibilidades do uso, de forma abrangente e acessível, de diversos métodos, materiais e recursos para apoiar suas práticas inclusivas e favorecer a participação de todos no processo de aprendizagem. Ao considerar a diversidade dos alunos, inclusive no que tange às necessidades de apoios específicos, pode-se pensar nas práticas de ensino a partir da proposta de universalização e focalização, que, de acordo com Marino (2017, p. 56), possibilita “[...] atender as especificidades, garantindo a universalização, respeitando as diferenças e combatendo as desigualdades [...]". Dessa forma, amplia-se o entendimento de que na perspectiva do ensino inclusivo, universalizar não é sinônimo de padronizar, e que propor ações focalizadas não diminui a capacidade dos alunos.

Para elaborar os conceitos de universalização e focalização no ensino precisamos refletir sobre a transitoriedade entre essas ações nas práticas docentes, com vistas à ampliação da participação de cada um e de todos. Para isso, cabe fazermos o seguinte questionamento: de que forma podemos definir a universalização e focalização a partir da atuação prática do professor nas salas de aula? Nas ações de universalização, o professor planeja o mesmo conteúdo e objetivo de aprendizagem, apresenta-os de múltiplas formas, maximizando o acesso e oportunizando que mesmo aqueles alunos que permaneciam às margens do aprendizado sejam alcançados pelas atividades. 
Ainda que sejam ofertados os múltiplos meios de acesso a todos os alunos, inclusive aqueles com deficiências ou dificuldades significativas, pode ocorrer que alguns não demonstrem condições para seguir o conteúdo proposto. Surge, então, a possibilidade da focalização no ensino, ou seja, diante desse contexto, o professor realiza uma reflexão sobre os objetivos e oferece recursos, estratégias e materiais que apoiem os estudantes nas dificuldades ou necessidades apresentadas.

Para elucidar, destacamos como exemplo a proposta desenvolvida em Portugal, que, no Decreto-Lei n. ${ }^{\circ}$ 54, de 2018, fundamenta a educação inclusiva a partir do Desenho Universal para Aprendizagem e propõe a abordagem multinível para acesso ao currículo, considerando que:

[...] baseia-se em modelos na opção por medidas de apoio à aprendizagem [...] organizadas em diferentes níveis de intervenção, de acordo com as respostas educativas necessárias para cada aluno adquirir uma base comum de competências, valorizando as suas potencialidades e interesses (PORTUGAL, 2018, p. 2919).

$\mathrm{Na}$ abordagem multinível, sugere-se uma organização com três níveis de intervenção para apoio às aprendizagens dos educandos, sendo eles: medidas universais, medidas seletivas e medidas adicionais. Trata-se de um modelo que se aproxima da proposta de universalização, ao oportunizar, nas medidas universais, o acesso de todos e cada um ao ensino e ao currículo. Quanto ao âmbito da focalização, são indicadas as medidas seletivas, para intervenção e acompanhamento às necessidades específicas de cada um, e as medidas adicionais, que preveem intervenções significativas, com adequações e/ou substituições do conteúdo, se necessário, para atender às necessidades individuais desses estudantes.

Para Mantoan (2003), a educação inclusiva necessita ser direcionada a partir das diferenças e não da igualdade assegurada pelo ideal de homogeneidade. Portanto, a escola inclusiva deve estimular potenciais e promover autonomia, oportunizando que todos aprendam de acordo com suas possibilidades.

\section{A pesquisa de campo: contribuições do DUA às práticas de ensino inclusivas}

Esta foi uma pesquisa que teve por objeto de estudo as práticas docentes inclusivas e as contribuições do Design Universal para Aprendizagem à construção de uma escola para todos. Assim, delineamos uma investigação que parte do conhecimento empírico, valorizando os conhecimentos adquiridos e as experiências do cotidiano. Sua natureza foi aplicada, pois gerou 
conhecimento para a prática, retornando à comunidade pesquisada com um curso de formação docente sobre o DUA.

\section{O percurso metodológico da pesquisa}

Os sujeitos participantes foram professoras da rede municipal de ensino, atuantes nas escolas de ensino fundamental do primeiro ao quinto ano de um município do ABCD paulista. Outro critério estabelecido para participação foi a manifestação de interesse em conhecer a proposta da abordagem do DUA. Acreditamos que o interesse favorece o desenvolvimento e as novas aprendizagens, pois "sem a curiosidade que me move, que me inquieta, que me insere na busca, não aprendo nem ensino" (FREIRE, 1996, p. 83).

Importa esclarecer que as professoras desconheciam a proposta do DUA. Para promover acesso ao conhecimento da abordagem e ampliar as possibilidades de discussões acerca das contribuições do DUA às práticas de ensino, oferecemos um seminário, organizado pelo Grupo de Pesquisa, com o tema "O Design Universal para Aprendizagem e a Inclusão Escolar", realizado em maio de 2020. Além disso, no primeiro encontro de roda de conversa, fizemos uma breve introdução teórica sobre os princípios e diretrizes da abordagem do DUA.

Iniciamos com a leitura e análise dos relatos de prática inclusiva e aproximação dessas práticas narradas à abordagem do Design Universal para Aprendizagem. Com o objetivo de organizar os dados colhidos nos relatos de memória docentes, optamos por seguir orientação do método de Freire (1979), que propõe três fases: o levantamento das palavras e temas mais significativos; a análise dos significados dos temas e palavras; apresentação de desafios ou situações-problema e debate acerca deles.

Desse modo, para o levantamento das palavras e temas significativos, buscamos identificar, nas situações do cotidiano narradas pelas professoras, os indicativos de saberes e fazeres comuns ao grupo. Assim, conforme fazíamos a leitura dos relatos, as tematizações dos três encontros se constituíam. Definimos os temas para os três encontros de roda de conversa: DUA sem saber; dificuldades e formação docente.

No tema do primeiro encontro, "DUA sem saber", retomamos os princípios e diretrizes da abordagem DUA como referencial. Buscamos perceber nos relatos quais as práticas docentes coadunavam-se com as propostas que consideravam os múltiplos meios de apresentação, engajamento e expressão com foco na participação e aprendizagem de todos os alunos.

A proposta dos múltiplos meios da abordagem do DUA ocorre quando o professor elabora estratégias abertas e diversificadas que possam ser exploradas de acordo com os interesses e as possibilidades de cada estudante. Como afirma Mantoan (2011, p. 65), o 
"professor que ensina a turma toda não tem o falar, o copiar e o ditar como recursos didáticos pedagógicos básicos". Ao contrário, esse professor busca compartilhar com os alunos "a construção/autoria dos conhecimentos" (MANTOAN, 2011, p. 65), deixando claro que o aluno é o centro do planejamento de ensino.

Aproximamos o princípio dos múltiplos meios de representação do conteúdo às práticas que indicavam uso de diversos recursos, que possibilitaram ampliar a compreensão dos alunos, como material concreto, material ampliado, vídeos, áudios, entre outros. Para a aproximação do princípio que propõe múltiplos meios de ação e expressão, destacamos práticas que indicavam as propostas variadas que incentivavam o uso de diferentes espaços, organizações de grupos de trabalho que permitiam aos alunos demonstrarem os saberes construídos ao longo do percurso e as formas utilizadas pelas professoras para avaliar as aprendizagens. No princípio de engajamento, verificamos as narrativas de propostas que partiam do interesse dos alunos, valorizando seus diversos saberes e preferências. Destacamos as que consideravam a motivação e o afeto como elemento essencial para a aprendizagem.

As dificuldades foram tema do segundo encontro, partindo das situações descritas pelas professoras que indicavam oportunidades para ampliar a reflexão acerca das contribuições dos princípios do DUA para o planejamento. Entre as dificuldades destacadas, estavam questões de comportamento, resistência dos alunos para participar da rotina e das propostas, falta de interação, falta de autonomia, dependência demasiada de apoios e os diagnósticos - entre eles as dificuldades de aprendizagem, os transtornos e as deficiências. Foi citada, ainda, a ausência de parceria com os professores especialistas para o planejamento.

O tema do terceiro encontro foi a formação docente. Apesar de não ficar explícito em todos os relatos a necessidade de ações de formação continuada, diante das dificuldades narradas, como sentimento de solidão e desamparo, percebemos que existe a inquietação e a necessidade de novos conhecimentos e de trocas com o coletivo por meio de reflexões "da" e "na” prática. Também se percebe a importância de conhecer e planejar adequações que atendam às especificidades dos alunos, contribuindo para a ressignificação dos saberes e fazeres nas práticas inclusivas.

Em razão das características próprias da roda de conversa enquanto instrumento de coleta de dados, nessa etapa foi possível, além de propor reflexões acerca dos temas, permitir que o diálogo fluísse livremente, de modo que as colocações de cada participante pudessem ser construídas a partir da escuta e da interação com os demais. Além disso, a diversidade esteve presente nos encontros, demonstrada pelas diferentes formas de engajamento, participação e posicionamento, bem como pelos silêncios, olhares, sorrisos e até mesmo pela distração de cada uma. 
A pesquisa de campo ocorreu no ano de 2020, por isso, enfrentamos alguns desafios no percurso, principalmente ocasionados pela situação de distanciamento, imposta pela pandemia de covid-19. Isso exigiu flexibilidade nos procedimentos metodológicos, os quais passaram a acontecer mediados pelas tecnologias e pelas adequações das propostas para interação com o grupo de participantes.

\section{Discussão e resultados}

As práticas inclusivas narradas nos relatos subsidiaram as reflexões e discussões acerca dos fazeres docentes no cotidiano de escola, proporcionando ao grupo uma identificação com a abordagem à medida que reconheciam que suas estratégias, recursos e propostas de ensino aproximavam-se dos princípios e diretrizes propostos pelo DUA. Tal percepção revelou que existe um interesse em estabelecer relação entre a teoria e as práticas educativas inclusivas no cotidiano da escola.

Os princípios do DUA orientam para um planejamento que ofereça múltiplos meios de representação, ação, expressão e engajamento para ampliar o acesso de todos os alunos à abordagem curricular. No entanto, essas práticas são mais perceptíveis nas propostas planejadas para os alunos PAEE na perspectiva da focalização das estratégias pedagógicas.

Discutir a oferta de múltiplos materiais, recursos e ferramentas evidenciou um entendimento equivocado dos professores quanto às questões de igualdade de direitos na escola. Esse conflito ocorre principalmente diante da carência desses recursos, os quais são insuficientes para todos os alunos nas escolas, ocasionando a decisão pelo uso direcionado dos recursos disponíveis na rotina escolar.

Nesse sentindo, o DUA provocou as professoras a repensarem o uso desses materiais e recursos, partindo da reflexão acerca da importância de se considerar as diferenças de todos os alunos no planejamento de ensino. Sendo os alunos o centro da proposta, o professor parte das singularidades, por isso, cada um vai requerer estratégias, recursos, ferramentas e apoios diferentes para participar das atividades.

Para o DUA, é necessário que sejam disponibilizados diferentes recursos que possam ser explorados a partir do interesse e da necessidade de cada um, de modo a incentivar a autonomia e o engajamento dos estudantes nas escolhas e no uso desses apoios para beneficiar seu processo de aprendizagem. Planejar ações que incentivam a escolha de forma autônoma dos alunos exige do professor flexibilidade e confiança no processo de desenvolvimento individual dos estudantes. Esse não é um processo simples, de acordo com o grupo de 
professoras, pois, muitas vezes, elas permanecem atreladas à ideia de que o aprendizado acontece somente quando estão presentes.

O intento de controlar as ações de ensino e aprendizagem encaminhou o grupo a discutir a tendência predominante ao planejamento único como forma de facilitar a organização da rotina e favorecer o acompanhamento dos professores em todas as atividades, o que nos levou a discutir a relevância do reconhecimento da diversidade dos e nos aprendizes. A proposta do DUA enfatiza a importância de, ao planejar, se considerar a variabilidade das formas de aprender dos alunos. Assim, esse novo paradigma contesta as práticas baseadas no modelo único de ensinar, o qual busca atender à sala toda com a mesma proposta. Isso levou as professoras a admitirem que, mesmo não intencionalmente, nem sempre os estudantes são considerados no planejamento.

No contexto das práticas inclusivas, o DUA sugere romper paradigmas e ressignificar o ensino para todos. Isso direcionou a reflexão do grupo ao currículo flexível, ampliando as discussões sobre a ação e a autonomia dos professores para definir, a partir da proposta curricular de cada escola, os objetivos, conteúdos, materiais e recursos para minimizar as barreiras de acesso ao conhecimento.

Discutiu-se muito no grupo sobre a necessidade de deixar explícitas as diferenças entre um currículo flexível e um currículo facilitado ou diminuído, principalmente no que tange ao planejamento das atividades destinadas (equivocadamente) somente aos alunos PAEE. Essa flexibilidade curricular importa na promoção dos meios para que todos aprendam nos seus próprios caminhos, minimizando a necessidade da adaptação curricular, algo defendido pelo DUA.

Outro ponto discutido pelo grupo diz respeito às ações de formação continuada em serviço e suas contribuições para as práticas inclusivas. O modelo recomendado pelo grupo coloca em questão o protagonismo e a valorização dos saberes e fazeres docentes. De acordo com as professoras, a formação precisa provocar a reflexão acerca das práticas, relacionar com a teoria e oportunizar um contínuo desenvolvimento profissional docente. Ou seja, torna-se fundamental retomar os temas discutidos, analisar se houve mudanças e repensar as próximas ações e reflexões. Nesse sentido, destaca-se o papel do formador como o problematizador que estabelece, a partir das situações do cotidiano relatadas pelos docentes, a relação entre o conteúdo teórico e provoca as discussões e reflexões em torno dos desafios elencados pelo grupo.

O grupo observou o quanto é necessário abrir espaços para que o professor possa falar sobre suas práticas e experiências, compartilhar um caso de ensino que deu certo, contar o que engajou os alunos, quais materiais e recursos foram utilizados e se os objetivos foram 
alcançados. Quando existe um espaço de diálogo e troca, segundo o grupo, a formação é dinâmica e favorece a interação entre os envolvidos.

O DUA vai ao encontro dessa proposta de formação dinâmica e interativa que valoriza a reflexão e as discussões sobre as práticas, tendo em vista atender às demandas do processo de inclusão escolar. O Design Universal para Aprendizagem busca apoiar os professores na construção da abordagem curricular acessível, o que demanda, necessariamente, a ressignificação de seus saberes e fazeres cotidianos.

\section{Considerações finais}

O processo de desenvolvimento profissional (etapas inicial e continuada) impacta os saberes e fazeres docentes significativamente. Por isso, consideramos que os conhecimentos alusivos à proposta da educação inclusiva devem estar presentes nessas etapas, subsidiando as ações no âmbito do exercício docente.

A partir da leitura dos relatos de memória docente, foi possível estabelecer relação entre as práticas de ensino e o DUA, colocando em destaque os desafios vivenciados no ensino em contexto de inclusão escolar. Além disso, refletimos sobre o acesso ao currículo escolar, tendo como premissa a variabilidade dos alunos e suas múltiplas formas de participação no processo de ensino.

Os múltiplos meios de representação, engajamento, ação e expressão propostos pela abordagem DUA podem provocar a percepção docente sobre o quanto o planejamento está baseado no padrão da monocultura, tornando-se excludente ao limitar ou impedir a participação dos aprendizes no percurso de aprendizagem escolar. Por isso, refletir e antecipar o planejamento a partir da abordagem do DUA estimula o professor a colocar a centralidade do aluno no processo de ensino, reconhecendo os diferentes ritmos e saberes de cada aprendiz.

Diante dessas constatações, os dados colhidos no decorrer das etapas desta pesquisa admitem que, de fato, o DUA pode contribuir para as práticas inclusivas dos professores, a partir da viabilização do seu acesso a essa proposta de abordagem curricular, por meio das ações de formação continuada fundadas nos espaços de diálogo e reflexão sobre as próprias práticas.

\section{REFERÊNCIAS}

BRASIL. Ministério da Educação. Secretaria de Educação Especial. Diretrizes nacionais para a educação especial na educação básica. Brasília: MEC / SEESP, 2001. 
BRASIL. Ministério da Educação / Secretaria de Educação Especial. Política Nacional de

Educação Especial na Perspectiva da Educação Inclusiva. 2008. Disponível em:

<http://portal.mec.gov.br/seesp/arquivos/pdf/politica.pdf>. Acesso em: 9 jul. 2019.

BRASIL. Ministério da Educação. Conselho Nacional de Educação. Câmara de Educação Básica. Resolução n..$^{\mathbf{4}}$, de 2 de outubro de 2009. Institui Diretrizes Operacionais para o Atendimento Educacional Especializado na Educação Básica, modalidade Educação Especial. 2009. Disponível em: <http://portal.mec.gov.br/dmdocuments/rceb004_09.pdf〉. Acesso em 10 ago. 2019.

CARVALHO, Rosita Edler. Escola Inclusiva: a reorganização do trabalho pedagógico. Porto Alegre: Mediação, 2014.

CAST. Universal Design for learning guidelines version 2.2. Massachusetts, 2018. Disponível em: <http://udlguidelines.cast.org/>. Acesso em: 16 jul. 2019.

COSTA-RENDERS, Elizabete Cristina. A escola inclusiva na perspectiva das pessoas com deficiência. Cad. Pesq., São Luís, v. 25, n. 3, jul./set. 2018. Disponível em: <http://www.periodicoseletronicos.ufma.br/index.php/cadernosdepesquisa/article/view/9950 >. Acesso em: 5 mar. 2020.

FREIRE, Paulo. Conscientização: teoria e prática da libertação: uma introdução ao pensamento de Paulo Freire. Trad. MELLO, K. S. São Paulo: Cortez \& Moraes, 1979.

FREIRE, Paulo. Pedagogia da autonomia: saberes necessários à prática educativa. São Paulo: Paz e Terra, 1996.

FREIRE, Paulo. Professora sim, tia não: cartas a quem ousa ensinar. São Paulo: Olho d’Água, 1997.

MACHADO, Rosângela. Educação inclusiva: revisar e refazer a cultura escolar. In: MANTOAN, M. T. E. (org.). O desafio das diferenças nas escolas. Rio de Janeiro: Vozes, 2011, p. 69-75.

MANTOAN, Maria Teresa Eglér. Inclusão escolar: o que é? por quê? como fazer? São Paulo: Moderna, 2003.

MANTOAN, Maria Teresa Eglér. Ensinando a turma toda: as diferenças na escola. In: MANTOAN, M. T. E. (org.). O desafio das diferenças nas escolas. Rio de Janeiro: Vozes, 2011, p. 59-67.

MAntoAn, Maria Teresa Eglér (org.). Em defesa da Política Nacional na Perspectiva da Educação Inclusiva: análise e manifestação sobre a proposta do Governo Federal de reformar a PNEEPEI (MEC/2008). Campinas: Leped / FE-Unicamp, 2018. Disponível em: $<$ https://inclusaoja.files.wordpress.com/2018/05/texto-de-anc3a1lise-dos-slides-sobre-areforma-da-pneepei-final1.pdf>. Acesso em: 23 nov. 2019.

MARCELO, Carlos Garcia. O professor iniciante, a prática pedagógica e o sentido da experiência. Form. Doc. - Revista Brasileira de Pesquisa sobre Formação de Professores, Belo Horizonte, v. 2, n. 3, p. 11- 49, ago./dez. 2010. 
MARINO, Virginia Gonçalves de Oliveira. Educação e pessoas com deficiência: a transitoriedade entre a universalização e a focalização. 2017. 135f. Dissertação (Mestrado em Educação) - Faculdade de Educação, Universidade de São Paulo, São Paulo, 2017.

MELRO, Joaquim de Jesus. Escola Inclusiva: uma história de amor (nem) sempre bem contada. 2003. Dissertação (Mestrado em Educação) - Faculdade de Ciências, Universidade de Lisboa, Lisboa, 2003.

MEYER, Anne.; ROSE, David H.; GORDON, David. Universal Design for Learning: theory and practice. EUA: CAST, 2014. Disponível em: <http://udlguidelines.cast.org/>. Acesso em: 16 jul. 2019.

NÓVOA, Antônio. Desafios do trabalho do professor no mundo contemporâneo. Sindicato dos professores de São Paulo, São Paulo: SINPRO/SP, 2006, p. 5-20. Palestra. Disponível em: <http://www.sinprosp.org.br/arquivos/novoa/livreto_novoa.pdf >. Acesso em: 12 abr. 2019.

NÓVOA, Antônio. Professores: imagens do futuro presente. Lisboa: Educa, 2009. PIMENTA, S. G. (org.). Saberes pedagógicos e atividade docente. São Paulo: Cortez, 2012.

PORTUGAL. Ministério da Educação. Direção-Geral da Educação. Para uma Educação Inclusiva: manual de apoio à prática. Lisboa: ME / DGE, 2018. Disponível em: $\langle$ https://www.dge.mec.pt/sites/default/files/EEspecial/manual_de_apoio_a_pratica.pdf $>$. Acesso em: 30 mar. 2020.

SANTOS, Amanda Gonçalves dos. O coordenador pedagógico e as reuniões pedagógicas possibilidades e caminhos. IV Encontro de Ensino, Pesquisa e Extensão da Faculdade Senac. PE. 2010. Disponível em: <http://www.faculdadesenacpe.edu.br/encontro-de-ensinopesquisa/2011/IV/anais/comunicacao/034_2010_ap_oral>.pdf. Acesso em 21 jun. 2021.

TARDIF, Maurice. Saberes docentes e formação profissional. Rio de janeiro: Vozes, 2014.

\section{SOBRE AS AUTORAS:}

\section{Adriana de Jesus Arroio Agostini}

Mestre em Educação pelo Programa de Pós-Graduação Stricto Sensu da Universidade Municipal de São Caetano (USCS). Trabalha como professora de educação básica na Prefeitura Municipal de Santo André, São Paulo. Membro do grupo de pesquisa ACESSI (Acessibilidade escolar e inclusão social). E-mail: adriarroio1@ gmail.com

(iD) https://orcid.org/0000-0002-1179-151X

\section{Elizabete Cristina Costa Renders}

Pós-Doutora e Doutora em Educação na área de Ensino e Práticas Culturais pela UNICAMP. Trabalha com a formação de professores no Programa de Pós-Graduação em Educação da Universidade Municipal de São Caetano do Sul. É líder do grupo de pesquisa ACESSI (Acessibilidade escolar e inclusão social). E-mail: elizabetecostarenders @ gmail.com (iD https://orcid.org/000 0-0002-1219-9382 